\title{
The application of organizational slack to hospital system responsiveness during the COVID-19 pandemic
}

\author{
John P. McHugh ${ }^{1}$, Dori A. Cross ${ }^{2}$ \\ ${ }^{1}$ Department of Health Policy and Management, Mailman School of Public Health, Columbia University, New York, NY, USA; ${ }^{2}$ Division of Health \\ Policy and Management, School of Public Health, University of Minnesota, Minneapolis, MN, USA \\ Contributions: (I) Conception and design: All authors; (II) Administrative support: None; (III) Provision of study materials or patients: None; (IV) \\ Collection and assembly of data: None; (V) Data analysis and interpretation: All authors; (VI) Manuscript writing: All authors; (VII) Final approval of \\ manuscript: All authors. \\ Correspondence to: John P. McHugh. Assistant Professor, Department of Health Policy and Management, Mailman School of Public Health, Columbia \\ University, 722 W 168th Street, 4th Floor, New York, NY 10032, USA. Email: jpm2192@cumc.columbia.edu.
}

\begin{abstract}
The COVID-19 pandemic placed intense pressure on individual hospitals and hospital systems. While no hospital could have predicted the exact needs required to respond to the crisis, there may be certain organizational characteristics or hospital system types that were better prepared to respond effectively. In this article, we propose a conceptual model for effectiveness of health system organizational response to COVID-19, using the theoretical foundation of organizational slack which is defined as the "excess" accumulated resources that do not contribute to that organization's immediate production function. We first define and describe the contributors of organizational slack, such as accumulated social capital or financial health. We then describe the benefits of organizational slack such as the ability to be more innovative or having more operational flexibility. Next, we discuss the application of organizational slack during the pandemic to adapt operations, redeploy staff and/or supplies and to manage any technological pivots (e.g., the rapid escalation of telehealth). Finally, we address the ways that hospital system structures may moderate the relationship between the benefits and applications of organizational slack. The COVID-19 pandemic placed unique pressures on hospitals as the crisis was sustained and will most likely transform future operations and care delivery. Through the lens of organizational slack, we can better understand the optimal ways to respond to future crises.
\end{abstract}

Keywords: Hospitals; hospital systems; organizational slack; pandemic response; crisis management

Received: 08 October 2020; Accepted: 18 February 2021; Published: 25 June 2021.

doi: $10.21037 /$ jhmhp-21-13

View this article at: http://dx.doi.org/10.21037/jhmhp-21-13

\section{Introduction/background}

In the first few weeks of the novel coronavirus disease 2019 (COVID-19) pandemic, some hospital capacity models predicted that hospital bed capacity may need to double in hard-hit areas like New York state (1). In Houston, a surge of COVID-19 infections starting in June created challenging capacity issues (2). In one particular hospital, the percent of hours that the hospital's emergency department was on diversion, over a similar 8-day period, grew from $2 \%$ in 2019 to $58 \%$ of the time in 2020 (2).
Hospitals adopted creative means to expand capacity. In one such example, Northwell Health, a hub-and-spoke system in the greater New York City area, was able to expand capacity by $50 \%$ in just two weeks by building bed units in auditoriums and conference rooms (1). Other hospitals developed protocols to reallocate patients across sites in the same system. The swiftness with which COVID-19 spread among communities required hospitals to be especially nimble, creative and innovative, and resourceful in order to respond and keep patients, staff and communities safe.

The demands that the pandemic forced on the healthcare 
system raise questions as to whether there are specific organizational characteristics that would facilitate a more innovative and effective response to an acute crisis, such as the COVID-19 pandemic. This may include issues around internal resource management such as staffing and supply chain (3), thinking creatively around space and facility planning (4), and rapidly ramping up technological capabilities that may not have been previously prioritized (e.g., telehealth) $(5,6)$. Further, an additional question that arises is whether there are certain hospital system structures that would moderate the ability of a hospital to effectively leverage these internal capabilities to facilitate the acute crisis response. A significant body of research has studied the relationship between health system form and financial performance (i.e. operating cost, efficiency, negotiated prices and/or profitability) (7-12). Financial health is a key indicator of resources for crisis response (13). However, system structure also affects the ways that decisions are made and resources are deployed; this critically affects mobilization during crisis response.

In this article, we propose a conceptual model for effectiveness of health system organizational response to COVID-19, using the theoretical foundation of organizational slack (14). "Organizational slack is that cushion of actual or potential resources which allows an organization to adapt successfully to internal pressures for adjustment or to external pressures for change in policy, as well as to initiate changes in strategy with respect to the external environment" (15). The benefits of organizational slack have been described as reducing conflict, easing planning and allowing for increased risk-taking (16). We argue for the importance of organizational slack and discuss factors that contribute to its accumulation. We then describe key domains of COVID response meaningfully shaped by the accumulation and accessibility of slack, and analyze the importance of a response strategy that is aligned with the benefits and challenges of different health system structures to achieve effective COVID response. Through the lens of slack, we then conclude by re-defining organizational recovery from COVID in terms of re-accumulation of, and a renewed focus on, slack.

\section{Theoretical context/analysis}

Neoclassical economic theory suggests organizations should operate at an optimal level of efficiency so as to maximize economic returns to the institution and organizational leaders and managers should all strive to achieve that goal (13).
However, in reality, most organizations operate with some level of "excess" that does not directly contribute to the immediate economic efficiency of the institution's operating model (13). In economic terms, this "excess" would be described as inefficient waste and would result in some level of disequilibrium (13). Management theory defines this "excess" as organizational slack (15). Since organizations typically operate in a context of environmental uncertainty, they accumulate slack resources that may emerge in the form of excess pay, under-utilized assets, or even charging below market prices (13). One could view organizational slack as a "hedge against the uncertainty in its planning" (16). It has been noted that organizational slack can be used as a mechanism for conflict resolution, a buffer against environmental discontinuities, a facilitator of organizational performance, a tool for legitimacy, a strategy for attracting and retaining staff, and a mechanism for innovation (13). Slack is typically considered as either a cache of resources for elevating effectiveness of everyday operations (i.e., well-trained staff, continuous quality improvement) or for facilitating short-term emergency response (i.e., a surge caused by a natural man-made disaster). We contribute to this understanding by specifically considering a middle ground of organizational response. Specifically, how is slack identified and deployed effectively in response to triggers (like COVID-19) that are emergent but (I) last many months, and (II) involve recovery back to a "new normal" where the event may fundamentally transform future operations and care delivery.

\section{Contributors to organizational slack}

There are several areas of a hospital's internal and external operations and environment that would contribute to optimal levels of organizational slack. Internally, financial health, leadership strength and accumulated social capital all help organizations accumulate slack. Externally, market competitiveness and historical crisis exposure may facilitate or activate slack accumulation (Figure 1).

\section{Financial bealth}

Financial slack allows organizations to manage through short-term crises and invest in areas of growth during normal operational periods (17). Hospitals and hospital systems able to accrue cash reserves over time are better positioned during an extended crisis to "weather the storm" and invest effectively in strategic changes that 


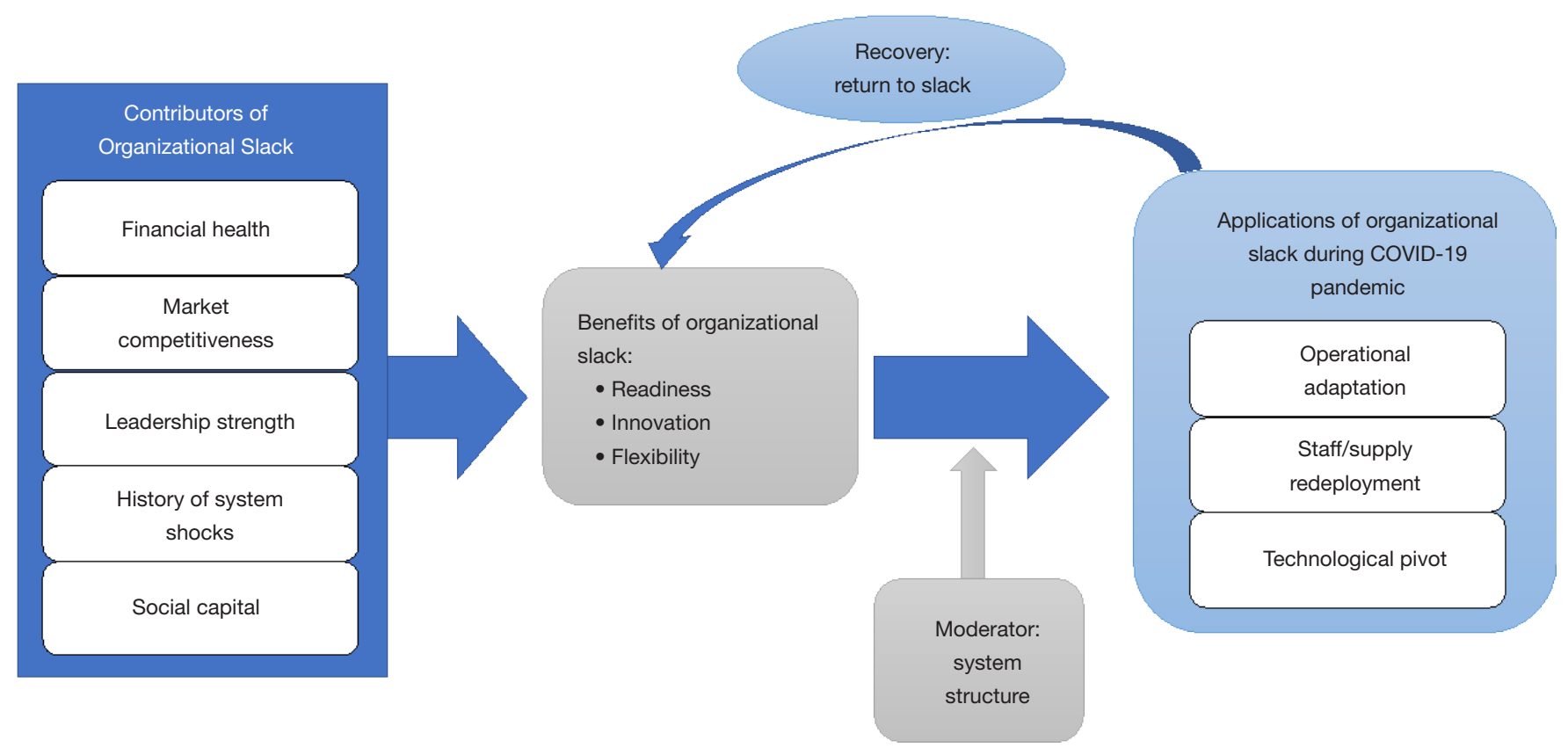

Figure 1 Slack diagram.

support sustained recovery. Specifically, hospitals that are able to develop efficient operating models that allow the organization to generate positive (or less negative) margins on Medicare patients (in addition to commercially insured patients) may exhibit greater financial "health" during crisis times (18). Those hospitals that are more reliant on commercial insurance margins alone, particularly for elective surgical care, may lack the financial flexibility to emerge from the pandemic in a strong position. These same facilities also may incur additional expense and inefficiency as they struggle to pivot operationally to provide the emergent services necessary during COVID or other acute crises.

\section{Leadership strength}

In a review of the research related to leadership in healthcare organizations, D'Aunno and Gilmartin write that "the search for heroic leaders probably reflects societies' (and researchers') continuing romance with leadership more than anything else" (19). Hospital leadership that is able to build a reserve of organizational slack would not be "heroic," but rather a leadership team able to motivate employees to achieve their fullest potential. In a study of Marines, individuals that were seen as part of the group and willing to follow were rated as more effective leaders (20). This is also consistent with D'Aunno and Gilmartin's conclusion “that leadership is positively and significantly associated with individual and group satisfaction, retention and performance" (19). Hospitals with strong leadership would lead an informed, urgent and transparent response, at the same time empowering others to innovate and continuously adapt to changing conditions at each phase of a prolonged crisis (21).

\section{Accumulated social capital}

Social capital accrues over time and provides organizations with the ability to "call on" these relationships in times of need (22). Uzzi's study of embeddedness demonstrated greater efficiency and adaptation among manufacturers in the New York City garment industry with stronger, more embedded relationships in their networks (23). Hospitals have shown to exhibit lower readmission rates for patients discharged to post-acute facilities where they have more embedded referral relationships (24-26). Through social capital and embedded relationships, hospitals are able to spread risk and vulnerability out across a broader network and leverage complementary advantages across different relationship partners to troubleshoot problems (23).

\section{Market competitiveness}

Hospitals that are in more competitive environments may 
accumulate more organizational slack because they will have a direct incentive to invest in their workforce and support innovation in order to attract new patients (27). In less competitive markets, hospitals may lack the incentives to innovate or build a more effective care delivery system. In more competitive markets, because of the dynamic environment, hospitals have a greater need to consistently accumulate and strategically deploy slack to respond to competitive threats as compared to hospitals in less competitive markets.

\section{Historical crisis exposure}

Recognizing the need to build reserves through prior crises may induce organizations to accumulate future reserves of slack. In a study of performance following the dot com bubble in the period from 2001-2003, organizations with higher levels of financial slack exhibited more rapid recovery from the recession (17). For hospitals, external shocks could come in the form of new policy (e.g., alternative payment models), competitive shifts (e.g., mergers), and/ or environmental crises (e.g., recession leading to delays in elective surgery). To mitigate the effects of the external shocks, hospitals may recognize the benefits of having organizational slack, thus building reserves for future use.

\section{Benefits of organizational slack}

Organizations build slack for various reasons depending on the market conditions and internal resource availability. In responding to sustained crises that may permanently alter organizational operations, organizations can utilize slack reserves to respond with more readiness, innovativeness, and flexibility.

\section{Readiness}

External shocks can materialize in different ways, such as a pandemic or other crisis, or a new federal or state policy. Slack resources benefit the organization by allowing a more efficient, effective, and timely response. For instance, only certain hospital systems responded to the initial alternative payment models introduced by the Affordable Care Act, such as bundled payments and accountable care organizations (28). It could be argued that those hospitals and hospital systems with the "readiness" to respond to value-based payments had greater slack resources to mitigate the risk associated with the transition and move earlier in response. As Zinn and Flood wrote, "firms with slack resources face a less narrow and idiosyncratic set of path-dependent options, allowing them to be more adaptive" (13).

\section{Innovation}

As it relates to innovation, research has shown that innovation is supported by having organizational slack. Several studies examined the relationship between organizational slack and research and development expenditures and patent applications, showing a positive association (27). The relationship, though, is U-shaped, meaning that having too much slack-particularly in terms of financial excess-is negatively associated with innovation, presumably because these organizations may lack exposure to competitive pressures that encourage responsive strategic thinking (27). This is also supported by research showing that firms with high levels of financial slack had more pronounced declines at the onset of a recession (17).

\section{Flexibility}

To the extent that slack implies a sufficient resource buffer for everyday operations, slack also enables organizational flexibility to rapidly and effectively use those resources in response to acute system shock. Particularly within the workforce, organizations with a culture of flexibility may be better able to alter schedules, reallocate staff coverage and even create new roles and/or team structures that evolve alongside an unfolding crisis (29). Coupled with strong leadership, hospitals with optimal levels of slack may be able to motivate their workforce to accept these changes and provide the necessary training and financial compensation for a more effective crisis response.

\section{Applications of organizational slack during extended response to COVID-19}

To combat the pandemic and survive its after affects, the organizational slack that a hospital accumulates can be deployed in several ways. First, a hospital can build on the innovation and readiness built into the hospital's culture to adapt operations to the changing environment. Second, hospitals with excess slack can more flexibly redeploy staff and supplies across a hospital system to where needs are the greatest. Third, slack allows hospitals to more quickly pivot technological resources to adapt to changing care needs. 
These factors allow hospitals to efficiently move patients across the continuum of care, manage surge capacity, and reallocate resources to keep patients and staff safe.

\section{Operational adaptation}

Hospitals in several regions of the country that experienced high rates of infection were forced to quickly adapt to volume surges that stressed existing capacity $(1,2)$. While the federal government provided some relief in certain areas with "pop-up" hospitals, naval hospitals, converted convention centers, the transfer of patients to these facilities was often challenging and it was then left to individual hospitals to convert existing space to enable them to care for sick patients $(1,30)$. This required very rapid innovation and creativity to transform auditoriums, cafeterias, conference rooms and other non-patient space into critical bed capacity.

As patients moved through the continuum of care, hospitals in regions with high COVID-19 transmission were struggling to ease capacity issues by discharging patients to post-acute and long-term care facilities (31). Hospitals with accumulated reserves of social capital and more embedded relationships with post-acute providers and other community-based organizations may have been more able to manage capacity and throughput during the crisis. For instance, hospitals with these embedded partnerships can work with facilities to identify isolation areas where COVID patients can be safely transitioned out of the hospital and into a nursing home environment for continued recovery (32).

\section{Staff/supply redeployment}

Research examining the relationship between organizational slack and personnel/staffing reveals that slack enables organizations to invest more in staff benefits in the form of higher pay, wellness benefits, flexible schedules, access to staffing reserves (e.g., temporary employees), and others (13). Pandemic response requires organizations to keep staff safe, cater to staff wellbeing, quickly replace staff that are temporarily quarantined, and mitigate against staff's risk of community spread (both contracting and spreading infection). Many hospitals offered bonuses and additional time-off for health care workers on the front lines of the crisis (33). The post-crisis mental health wellbeing of frontline health care workers will also be critical to the pandemic response $(34,35)$. Organizations needed slack to act with urgency to address both the short and long-term implications of the crisis on sufficient staffing and staff wellbeing. This slack facilitates adding enhanced benefits for personnel and staff such as hazard pay during the crisis and more costly, but targeted benefits, to address post-pandemic mental health needs.

Procuring PPE during the pandemic became a challenge for many hospital systems and many had to turn to novel and creative solutions (36). The social capital that accumulates with organizational slack could have allowed some hospital systems to respond more flexibly to supply chain discontinuities amidst the environmental threat of the coronavirus as hospitals were able to lean on supply chain relationships and other key constituents (e.g., Board members) to procure necessary supplies $(13,15,37)$. Further, those hospitals that recognized the value of supply chain leaders and/or invested in new technology to manage the supply chain would have been better positioned to respond to the pandemic (38).

\section{Technological pivot}

The onset of the coronavirus pandemic led to a rapid shift away from in-person physician office visits and replacing those with telehealth visits $(5,6)$. Research on telehealth adoption showed that hospitals that were more technologically advanced were more likely to have adopted telehealth capabilities (39). Further, larger hospitals, hospitals affiliated with a health system, teaching hospitals and not-for-profit hospitals were all characteristics associated with greater telehealth adoption (39). Organizations with the slack to invest more proactively in technological scale would most likely predict the ability of that system to rapidly scale up telehealth capabilities during the pandemic. In addition, those organizations further along in interoperability (i.e., within their own health system and with affiliated organizational partners) would be better positioned to move patients around and utilize space across the network, capable of a smoother transition and information availability at all points of care.

All of these factors are consistent with organizational slack, as to execute on each in the face of a crisis such as a pandemic requires additional resources and focus that do not exist without organizational slack. However, drawing out and deploying slack is highly context-dependent; effective pandemic response can and should look different based on the organizational structure (16). Here, we focus on inter-organizational structure within integrated health systems as a key factor to consider given the sweeping 
mobilization necessary in a sustained crisis such as COVID-19.

\section{System structure as a moderator of organizational slack accumulation}

As hospitals accumulate slack and apply it to their pandemic response, the question arises as to whether the system type to which the hospital belongs may moderate the link between slack and pandemic response. Geographic distribution, "systemness," or member heterogeneity, among others, may all be system characteristics that can either facilitate or impede the link between slack resources and how they are used to respond to the coronavirus pandemic. First, though, we must define the parameters of a hospital "system."

\section{Defining hospital systems}

In 2018, there were 637 health systems in the United States and $71.8 \%$ of hospitals were part of a health system. Sixtynine percent of health systems were not-for-profit, $20 \%$ were public/government, $8 \%$ were church operated and 3\% were for-profit (40). However, these system designations do not help to distinguish performance across hospital markets and/or define the ways they accumulate slack resources. Bazzoli et al. developed one of the early taxonomies that considered centralization as a key parameter aligned with performance (41). This research led to a taxonomy of five system types (centralized health systems, centralized physician/insurance health systems, decentralized health systems, moderately centralized health systems, independent health systems) that exists today as a unique variable in the American Hospital Association survey. Burns et al. built on the Bazzoli model, but also considered geographic "reach" as a key parameter of system performance, leading to three system types (national, hub and spoke, regional) (7). They define national systems as those that operate in 3 or more states or where the hospitals are 300 or more miles apart from each other, on average. Hub-and-spoke systems were those with less than or equal to 100 miles between hospitals, variation in hospital size and at least one COTH member (7). All other systems were categorized as regional. As it relates to organizational slack, these models can help to illuminate differences in how a hospital most effectively deploys slack to respond to an external crisis such as the coronavirus pandemic.

For the purposes of defining organizational slack in the context of a pandemic, we will apply the Burns et. al. model supplemented by Bazzoli's concept of centralization, as that allows us to consider the geographic reach of a hospital system across varying levels of centralization that is critical to understanding how the hospitals will perform in a crisis.

\section{Predicted system responsiveness}

Considering the types of hospital systems based on geographic reach, there are areas where certain types would be expected to perform better in a crisis. In Table 1, the description of hospital system types based on the Burns et al. definition vis-à-vis the key areas of slack application (operational adaptation, staff/supply redeployment, and technological pivot) is shown.

\section{National systems}

Given the geographic spread of national systems (i.e., operating in 3 or more states, or where hospitals are 300 or more miles apart from each other, on average), these systems have a scale that achieves financial health through lower borrowing costs and centralized administrative functions (7). However, in a highly centralized national system, innovation and operational adaptation will most likely be limited as compared to national systems that encourage more local autonomy where more innovative hospital cultures can emerge.

The scale of national systems suggests that they might have broader reach in sourcing temporary staffing for high infection rate areas. The national scale would also most likely translate to greater supply chain redeployment. Here, a higher level of centralization is desired where supply chain decisions are made and monitored at the national level and would allow for more efficient movement of supplies across the system.

National systems are likely to have robust technological capabilities, given the scale at which they make investments in EHR vendor products and other assistive information and communication technologies (i.e., to support telehealth). However, given the geographic spread of these systems, they may not have invested in IT-assisted processes for provider cross-coverage across systems or for moving patients around in response to surge. National systems would also not necessarily have invested resources in building local social capital. Here, less centralized systems with local autonomy may accrue more social capital in select markets where it aligns with individual hospital needs. 
Table 1 Applications of slack vis-à-vis hospital system types

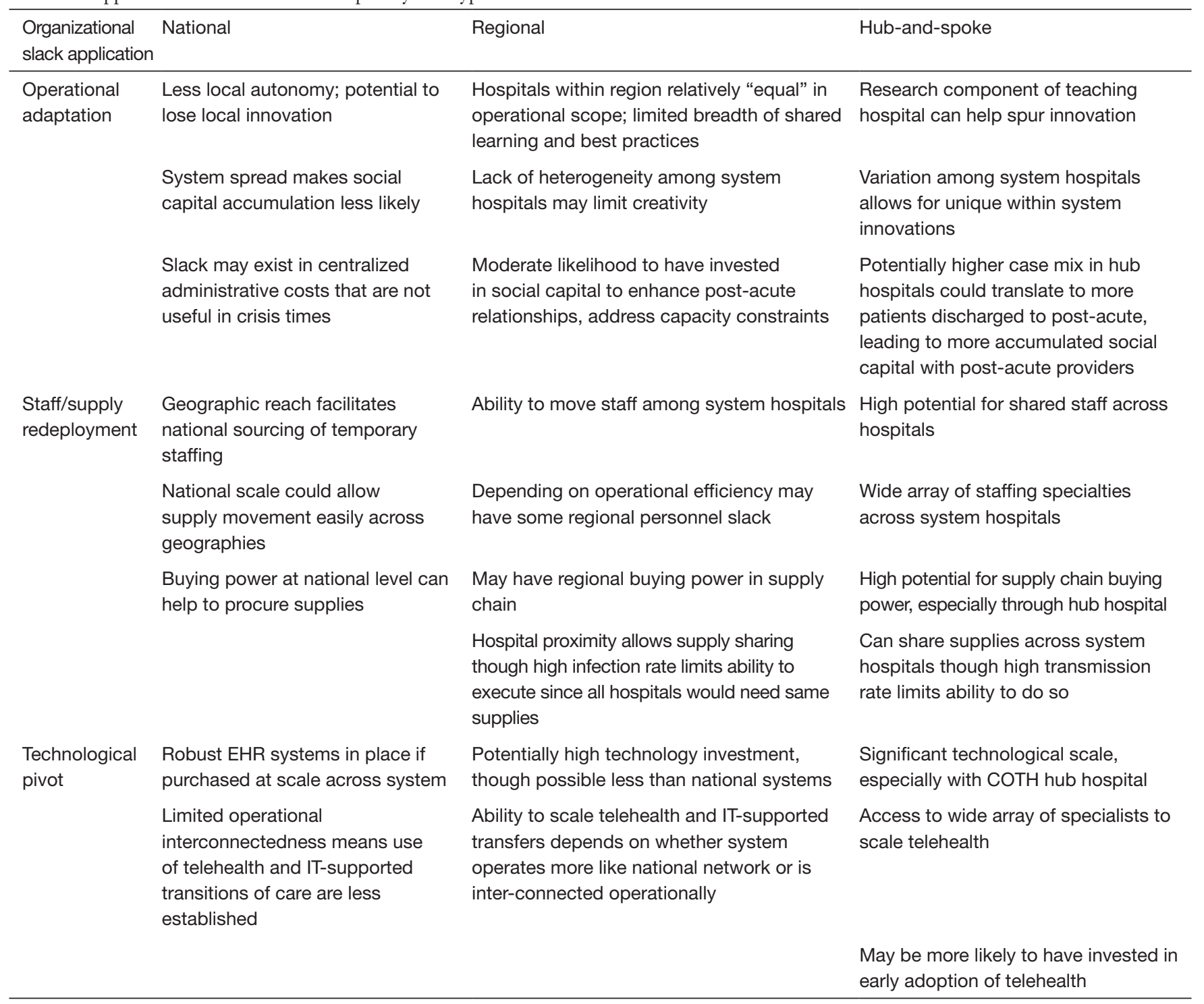

\section{Regional systems}

Regional systems do not have the same geographic spread as national systems but are still able to coordinate efforts across a regional footprint. The local/regional scale may also enable a system to negotiate with payers collectively, achieving higher reimbursement rates and greater financial strength. In a regional system, the hospitals may be more able to share best practices and even visit system hospitals to observe various innovations and operational adaptations.

It would be easier for regional systems to move staff among system hospitals given the geographic proximity. For those systems with more organizational slack, it may be easier to "flex-up" staff as well during any volume surges. Regional systems may have regional buying power in the supply chain and, proximity allows for sharing supplies. However, if the transmission rate is high across a region, there would be need across all system facilities and less ability to reallocate supplies.

Regional systems are more likely than national systems to not only have robust EHRs but also have already worked through how to leverage information and communication technologies for supporting inter-organizational crosscoverage and patient transfers. Their ability to scale up telehealth during a pandemic crisis likely depends on whether they operate more like a national network or have 
more regional interconnectedness. Regional systems may also be more likely to have invested time in developing post-acute networks and achieving a high level of social capital and organizational embeddedness where the hospital can work with post-acute facilities to move patients across the continuum of care and reduce the capacity burden of sick patients.

\section{Hub-and-spoke systems}

Hub-and-spoke systems should have the optimal level of organizational slack to effectively respond to a pandemic or other similar crisis. Hub-and-spoke systems may not have the healthiest financial position due to the possibility that hub teaching hospitals may serve as safety net facilities and treat complex patients with higher than average Medicaid populations. However, the slack that emerges in an environment where efficiency is built in to address low reimbursement rates means the system can more easily mitigate the risk of losing cross-subsidization of commercially insured patients. Further, innovation in these facilities emerge from a culture of research and, thus, facilitate the adaptation necessary to respond to a crisis. Finally, the heterogeneity in the size and scope of hospitals within the hub-and-spoke systems can help to provide some financial flexibility. Moderately centralized hub-and-spoke systems where local autonomy is supported by diffusion of best practices and research make this type of system ideal for addressing a pandemic.

The proximity of hospitals in a hub-and-spoke system means that staff can be shared among the system hospitals. More importantly, though, given the variation in scope of the services offered at system hospitals, patients can more easily be reallocated to the proper hospital setting in order to keep patients safe and possibly consolidate infected patients to one or two hospitals. With a technologically advanced hub hospital, the supply chain capabilities should be fairly strong in these hospital systems and the proximity allows for storage and redistribution of supplies in system facilities.

The hub hospitals in the hub-and-spoke systems will be some of the most technologically advanced facilities across the country. Therefore, they will be able to scale technologies such as telehealth during a pandemic but will also be able to provide access to a wide array of specialists and sub-specialists even during times when in-office visits are limited. Given the complexity of patients (i.e., higher case mix) at hub hospitals in these systems, it is more likely that the system would have a preferred network of post-acute providers which means the system would be well-positioned to work with the network of providers to efficiently and safely move patients out of the hospital and into a post-acute bed.

Hub-and-spoke systems appear to have the optimal level of geographic reach, heterogeneity across system membership, and a focus on research and innovation that would allow them to respond most effectively to a pandemic. Further, given the higher expected case mix of patients at the hub teaching facilities, staff and leadership in these hospitals are used to caring for complex patients and managing complicated funds flow models where Medicare and Medicaid are the dominant payers. Where national systems may exhibit more organizational slack in the form of higher administrative costs, and regional systems may lack an adequate level of slack given the lack of variation across hospital sizes and scopes, the hub-and-spoke system model accumulates slack that can be used to invest in innovation and specialty staff, address the environmental discontinuities and allows for a quicker recovery period since the hospitals have built operational efficiency around a less than desirable payer mix.

\section{Discussion}

Organizational slack has useful applications for understanding how healthcare systems respond to the extremes of chronic and acute organizational pressures, i.e., general environmental uncertainty in everyday operations as well as external threat from sudden emergencies. We posit that slack also has application for mid-range crises such as that caused by the coronavirus pandemic, where the disruption is sustained and likely leads to a recovery with more permanent organizational changes. As hospitals need to think about the operational adaptation, staff and supply redeployment, and technological pivot required, they can access the responsiveness, innovation and flexibility that resides within the organization. Slack in hospitals can be accumulated through financial health, market competitiveness, leadership strength, history of market disruptions and social capital. There are, though, ways in which slack can impede pandemic response such as administrative slack that does not necessarily directly improve clinical operations. Achieving optimal levels of slack can be facilitated through system development as hospitals can work together to achieve efficiencies, share best practices, and redeploy assets and workforce in the 
regular course of business that can then be applied to pandemic response. However, the ability of hospital systems to optimize slack will vary depending on how the system is organized and the balance between local and centralized decision-making.

As it relates to the pandemic, hub-and-spoke systems, especially those that are moderately concentrated should have the greatest ability to accumulate organizational slack that can be applied to the organizational adaptation, staff and supply redeployment and technological pivot required to respond to the changing environment. These systems have variation in bed allocation across their hospitals (i.e., mix of ICU and general medical/surgical beds), high levels of technology investment, and the research focus of the teaching hospitals should help them innovate. Further, the teaching hospitals are often more apt to treat more complex, high-need patients, a skill that would allow them to adapt to the complex needs of COVID-19 patients. National systems may be in a good position to redeploy supplies and may be able to tap broader networks for temporary staffing solutions. But, to the extent there is a sizeable national office, the system may have accumulated high levels of administrative slack that is not urgently responsive to dynamic local needs and does not necessarily help during a pandemic crisis (7). If national systems are able to organize their hospitals into hub-and-spoke regional systems, they may be able to replicate the benefits of the hub-and-spoke model. Regional systems may be impeded by the fact that the hospitals in these systems could be somewhat homogeneous in size and service scope and in the populations served. This lack of heterogeneity could make it more difficult to respond as the varied skill levels required to combat the pandemic may be lacking.

Equally important to the application of slack resources during a crisis, hospitals will need to think about recovery and ways to return to slack. It is also important to consider renewed investments in accumulating slack through greater staff cross-training, enhanced social capital through greater interconnectedness, and continued investment in hybrid care models with telehealth. Investments such as those will help hospitals manage future crises, and, perhaps, will force new hospital-to-hospital partnerships, partnerships with post-acute and other providers and partnerships with community organizations. One significant challenge for health systems looking to accumulate and maintain the "right amount" of slack is the lack of a synthesized and validated measure of this concept. Hospital and hospital system bond ratings, which reflect a comprehensive assessment of the riskiness of investing in that entity, offer one such indicator. However, often hospitals and hospital systems don't know the adequacy of organizational slack until it is actively being tested. A promising area of future work is to use evidence from COVID-19 response and other recent healthcare market shocks to develop and test a measure of organizational slack that can be used more proactively for hospital system development and operations.

Finally, as merger and acquisition activity in the hospital sector continues, it is worth considering how different systems may or may not be able to accumulate the optimal level of organizational slack to respond to external threats such as a pandemic (42). Perhaps, this will also accelerate the growth of provider sponsored insurance plans as hospital systems realize the benefits of controlling risk within a portion of their population. It may also be the case that national systems continue to move away from markets where they own one or two individual hospitals and attempt to build regional hub-and-spoke models that can generate more "systemness." COVID-19 certainly stressed hospital operations, especially in those areas such as New York City with high infection rates. The next few years should see hospital systems reorganizing and optimizing their operating models to optimize slack resources in order to best respond to future crises.

\section{Acknowledgments}

Funding: None.

\section{Footnote}

Provenance and Peer Review: This article was commissioned by the Guest Editors (Erick Guerrero and Jemima A. Frimpong) for the series "Organizational Approaches to Implement Rapid Change in Hospitals to Respond to Public Health Emergencies" published in Fournal of Hospital Management and Health Policy. The article has undergone external peer review.

Conflicts of Interest: Both authors have completed the ICMJE uniform disclosure forms (available at http://dx.doi. org/10.21037/jhmhp-21-13). The series "Organizational Approaches to Implement Rapid Change in Hospitals to Respond to Public Health Emergencies" was commissioned by the editorial office without any funding or sponsorship. 
The authors have no other conflicts of interest to declare.

Ethical Statement: The authors are accountable for all aspects of the work in ensuring that questions related to the accuracy or integrity of any part of the work are appropriately investigated and resolved.

Open Access Statement: This is an Open Access article distributed in accordance with the Creative Commons Attribution-NonCommercial-NoDerivs 4.0 International License (CC BY-NC-ND 4.0), which permits the noncommercial replication and distribution of the article with the strict proviso that no changes or edits are made and the original work is properly cited (including links to both the formal publication through the relevant DOI and the license). See: https://creativecommons.org/licenses/by-nc-nd/4.0/.

\section{References}

1. Ornstein C. ProPublica. How America's Hospitals Survived the First Wave of the Coronavirus. [Online] June 15, 2020. Available online: https://www.propublica.org/ article/how-americas-hospitals-survived-the-first-wave-ofthe-coronavirus

2. Hixenbaugh M, Ornstein C. NBC News. 'All the hospitals are full': In Houston, overwhelmed ICUs leave COVID-19 patients waiting in the ER. [Online] July 10, 2020. Available online: https://www.nbcnews.com/news/ us-news/all-hospitals-are-full-houston-overwhelmed-icusleave-covid-19-n1233430

3. Mirchandani P. Health Care Supply Chains: COVID-19 Challenges and Pressing Actions. Ann Intern Med 2020;173:300-1.

4. Burmahl B. Pandemic adds considerations for health care facility planning. Health Facil Manage 2020 Jun 18. [Online] Available online: https://www.hfmmagazine.com/ articles/3935-pandemic-adds-considerations-for-healthcare-facility-planning

5. Lee T. Creating the New Normal: The Clinical Response to Covid-19. NEJM Catalyst 2020. Available online: https://catalyst.nejm.org/doi/full/10.1056/CAT.20.0076

6. Mehrotra A, Ray K, Brockmeyer DM, et al. Rapidly Converting to Virtual Practices: Outpatient Care in the Era of Covid-19. New Engl J Med Catalyst 2020. doi: 10.1056/CAT.20.0091.

7. Burns LR, McCullough JS, Wholey DR, et al. Is the System Really the Solution? Operating Costs in Hospital Systems. Med Care Res Rev 2015;72:247-72.
8. Bazzoli GJ, Chan B, Shortell SM, et al. The Financial Performance of Hospitals Belonging to Health Networks and Systems. Inquiry 2000;37:234-52.

9. Büchner VA, Hinz V, Schreyugg J. Health systems: changes in hospital efficiency and profitability. Health Care Manag Sci 2016;19:130-43.

10. Holmgren AJ, Ford EW. Assessing the impact of health system organizational structure on hospital electronic data sharing. J Am Med Inform Assoc 2018;25:1147-52.

11. Dranove D, Lindrooth R. Hospital consolidation and costs: another look at the evidence. J Health Econ 2003;22:983-97.

12. Dafny L, Ho K, Lee RS. The price effects of cross-market mergers: theory and evidence from the hospital industry. RAND J Econ 2019;50:286-325.

13. Zinn J, Flood AB. Commentary: Slack Resources in Health Care Organizations - Fat to Be Trimmed or Muscle to be Exercised? Health Serv Res 2009;44:812-20.

14. Oviatt BM. Agency and Transaction Cost Perspectives on the Manager-Shareholder Relationship: Incentives for Congruent Interests. Acad Manage Rev 1988;13:214-25.

15. Bourgeois LJ. On the Measurement of Slack. Acad Manage Rev 1981;6:29-39.

16. Naslund B. Organizational Slack. Ekonomisk Tidskrift 1964;66:26-31.

17. Latham SF, Braun MR. The Performance Implications of FInancial Slack during Economic Recession and Recovery: Observations from the Software Industry (2001-2003). J Manag Issues 2008;20:30-50.

18. Goldsmith J, Bajner R. 5 Ways U.S. Hospitals Can Handle Financial Losses from Medicare Patients. Harvard Business Review; 2017.

19. Gilmartin MJ, D'Aunno TA. 8. Leadership Research in Healthcare: A Review and Roadmap. Acad Manag Ann 2007;1:387-438.

20. Peters K, Haslam SA. I follow, therefore I lead: A longitudinal study of leader and follower identity and leadership in the marines. Br J Psychol 2018;109:708-23.

21. Kerrissey MJ, Edmondson AC. What Good Leadership Looks Like During This Pandemic. Harvard Business Review; 2020.

22. Adler PS, Kwon SW. Social Capital: Prospects for a New Concept. Acad Manage Rev 2002;27:17-40.

23. Uzzi, B. Social Structure and Competition in Interfirm Networks: The Paradox of Embeddedness. Adm Sci Q 1997;42:35-67.

24. McHugh JP, Shield RR, Gadbois EA, et al. Readmission Reduction Strategies for Patients Discharged to Skilled 
Nursing Facilities: A Case Study From 2 Hospital Systems in 1 City. J Nurs Care Qual 2021;36:91-8.

25. McHugh JP, Foster A, Mor V, et al. Reducing Hospital Readmissions Through Preferred Networks of Skilled Nursing Facilities. Health Aff (Millwood) 2017;36:1591-8.

26. Shield R, Winblad U, McHugh J, et al. Choosing the Best and Scrambling for the Rest: Hospital-Nursing Home Relationships and Admissions to Post-Acute Care. J Appl Gerontol 2019;38:479-98.

27. Herold DM, Jayaraman N, Narayanaswamy CR. What is the relationship between organizational slack and innovation? J Manag Issues 2006;18:372-92.

28. Shortell SM, Wu FM, Lewis VA, et al. A Taxonomy of Accountable Care Organizations for Policy and Practice. Health Serv Res 2014;49:1883-99.

29. Paraskevas A. Crisis management or crisis response system? A complexity science approach to organizational crises. Manag Decision 2006;44:892-907.

30. Chappell B, Hersher R. In New York, Overflow Hospitals At Javits And On Navy Ship Have Been Largely Empty. NPR WNYC 2020 Apr 6 [Online]. Available online: https://www.npr.org/sections/coronavirus-liveupdates/2020/04/06/827995726/in-new-york-overflowhospitals-at-javits-and-on-navy-ship-have-been-largely-empt

31. Crimaldi L. With diligence and luck, some nursing homes have kept the virus out. Boston Globe 2020 Jun 2. [Online] Available online: https://www.bostonglobe. com/2020/06/02/nation/with-diligence-luck-somenursing-homes-have-kept-virus-out/

32. Herzenberg M. Is New York's Policy Putting Nursing Home Residents at Risk of Catching COVID-19? Spectrum News NY 12020 Apr 23. [Online] Available online: https://www.ny1.com/nyc/all-boroughs/ news/2020/04/22/new-york-nursing-home-coronaviruspatient-policy-

33. Gooch K. 8 hospitals giving workers COVID-19 bonuses. Becker's Hospital Review 2020 Jul 1 [Online] Available online: https://www.beckershospitalreview.com/ compensation-issues/8-hospitals-giving-workers-covid-19-

doi: $10.21037 /$ jhmhp-21-13

Cite this article as: McHugh JP, Cross DA. The application of organizational slack to hospital system responsiveness during the COVID-19 pandemic. J Hosp Manag Health Policy 2021;5:17. bonuses.html

34. Spoorthy MS, Pratapa SK, Mahant S. Mental health problems faced by healthcare workers due to the COVID-19 pandemic - A review. Asian J Psychiatr 2020;51:102119.

35. IHI Multimedia Team. Preparing for COVID-19's Impact on the Mental Health of the Health Care Workforce. Institute for Healthcare Improvement 2020 Jun 10. [Online] Available online: http://www.ihi.org/ communities/blogs/preparing-for-covid-19-s-impact-onthe-mental-health-of-the-health-care-workforce

36. Jewett C, Weber L. Hospital suppliers take to the skies to combat dire shortages of COVID-19 gear. Modern Healthcare 2020 Mar 26. [Online] https://www. modernhealthcare.com/safety-quality/hospital-supplierstake-skies-combat-dire-shortages-covid-19-gear

37. Cyert RM, March JG. A Behavioral Theory of the Firm. Englewood Cliffs: Prentice-Hall, 1963.

38. King R. Hospitals employ lessons learned in load balancing, supply chain as COVID-19 cases surge. Fierce Healthcare $2020 \mathrm{Jul}$ 27. [Online] Available online: https:// www.fiercehealthcare.com/hospitals/hospitals-applylessons-learned-supply-chains-load-balancing-to-combatrising-covid-19

39. Adler-Milstein J, Kvedar J, Bates DW. Telehealth Among US Hospitals: Several Factors, Including State Reimbursement and Licensure Policies, Influence Adoption. Health Aff (Millwood) 2014;33:207-15.

40. Furukawa M, Kimmey L, Jones DJ, et al. Consolidation And Health Systems In 2018: New Data From The AHRQ Compendium. Health Aff Blog 2019. doi: 10.1377/ hblog20191122.345861.

41. Bazzoli GJ, Shortell SM, Dubbs N, et al. A Taxonomy of Health Networks and Systems: Bringing Order Out of Chaos. Health Serv Res 1999;33:1683-717.

42. Daly R. More hospital consolidation is expected postpandemic. HFMA 2020 Aug 10 [Online] Available online: https://www.hfma.org/topics/news/2020/08/morehospital-consolidation-is-expected-post-pandemic.html 